Correction

\title{
Correction: Chae, H.S.; et al. Atractylodin Inhibits Interleukin- 6 by Blocking NPM-ALK Activation and MAPKs in HMC-1. Molecules 2016, 21, 1169
}

\author{
Hee-Sung Chae, Young-Mi Kim and Young-Won Chin * \\ College of Pharmacy, Dongguk University-Seoul, 32 Dongguk-lo, Ilsandong-gu, Goyang-si, \\ Gyeonggi-do 410-820, Korea; chaeheesung83@gmail.com (H.-S.C.); 0210121@hanmail.net (Y.-M.K.) \\ * Correspondence: f2744@dongguk.edu; Tel./Fax: +82-31-961-5218 \\ Academic Editor: Derek J. McPhee \\ Received: 12 October 2016; Accepted: 19 October 2016; Published: 25 October 2016
}

The authors wish to make the following correction to their paper [1]. In Panel D of Figure 2, the data was incorrectly displayed. The correct version of Figure 2D is as follows:

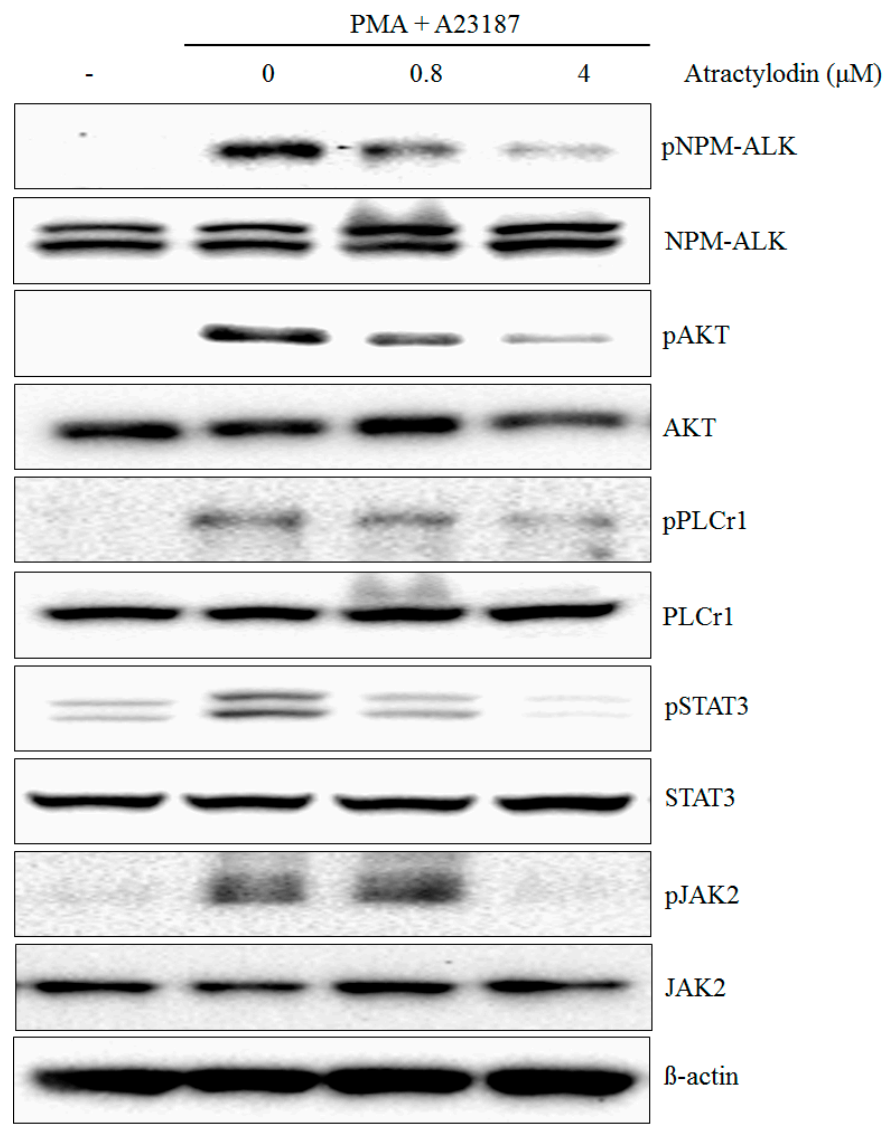

Figure 2. (D) HMC-1 was treated with the indicated concentrations of Atractylodin for $0.5 \mathrm{~h}$ prior to being incubated with PMA $(50 \mathrm{nM})$ plus A23187 $(1 \mu \mathrm{M})$ for $0.5 \mathrm{~h}$ and phospho and total NPM-ALK, AKT, PLC $\gamma 1$, JAK2, and STAT3 were detected by immunoblot analysis as described in Materials and Methods.

The change does not affect the scientific results. The manuscript will be updated and the original will remain online on the article webpage. The authors would like to apologize for any inconvenience caused to readers by these changes. 


\section{Reference}

1. Chae, H.S.; Kim, Y.M.; Chin, Y.W. Atractylodin Inhibits Interleukin-6 by Blocking NPM-ALK Activation and MAPKs in HMC-1. Molecules 2016, 21, 1169. [CrossRef] [PubMed]

(c)

(C) 2016 by the authors; licensee MDPI, Basel, Switzerland. This article is an open access article distributed under the terms and conditions of the Creative Commons Attribution (CC-BY) license (http:/ / creativecommons.org/licenses/by/4.0/). 